\title{
Correction to: Ultrashort time-to-echo quantitative magnetic resonance imaging of the triangular fibrocartilage: differences in position
}

\author{
Akitaka Fujisaki ${ }^{1} \cdot$ Takatoshi Aoki $^{1} \cdot$ Hidekuni Narimatsu $^{1} \cdot$ Chie Kuwahara $^{1} \cdot$ Atsushi Nozaki $^{2} \cdot$ Kunitaka Menuki $^{3}$. \\ Akinori Sakai $^{3} \cdot$ Yukunori Korogi $^{1}$
}

Published online: 19 February 2019

(C) European Society of Radiology 2019

\section{European Radiology \\ https://doi.org/10.1007/s00330-018-5693-7}

The original version of this article, published on 03 September 2018, unfortunately contained a mistake. The following correction has therefore been made in the original: The presentation of Table 1 was incorrect. The corrected table is given below. The original article has been corrected.

Table 1 Average T2* values of TFC of the wrist according to the forearm/wrist position

\begin{tabular}{lcll}
\hline Postion & Neutral & Pronation & Ulnar flexion \\
\hline mean \pm 2SD (ms) & $10.08 \pm 1.90$ & $7.92 \pm 1.37$ & $9.15 \pm 1.03$ \\
& \multicolumn{2}{c}{$\longleftarrow$} \\
\hline
\end{tabular}

$* p<0.017$ (two-tailed Wilcoxon signed-rank test)

Publisher's note Springer Nature remains neutral with regard to jurisdictional claims in published maps and institutional affiliations.

The online version of the original article can be found at https://doi.org/ 10.1007/s00330-018-5693-7

Takatoshi Aoki

a-taka@med.uoeh-u.ac.jp

1 Department of Radiology, University of Occupational and Environmental Health, 1-1 Iseigaoka, Yahatanishi-ku, Kitakyushu 807-8555, Japan

2 MR Applications and Workflow, Asia Pacific, GE Healthcare, Tokyo, Japan

3 Department of Orthopaedic Surgery, University of Occupational and Environmental Health, Kitakyushu, Japan 